\title{
Ensino de Biofísica: entre o equilíbrio, o desequilíbrio e a auto-organização em sistemas biológicos
}

\author{
Mayara Gomes da Silva \\ Mestranda em Ensino de Ciências e Educação Matemática \\ Especialista em Desenvolvimento Humano e Educação Escolar \\ Grupo de Estudos da Complexidade e da Vida \\ Universidade Estadual da Paraíba - UEPB, Campina Grande/PB \\ $\triangle \underline{\text { mayaragomesec@gmail.com }}$ \\ Márcia Adelino da Silva Dias \\ Doutora em Educação (UFRN) \\ Professora Associada do Departamento de Biologia \\ Grupo de Estudos da Complexidade e da Vida \\ Universidade Estadual da Paraíba - UEPB, Campina Grande/PB \\ Karla Patrícia de Oliveira Luna \\ Doutora em Saúde Pública (FIOCRUZ/PE) \\ Professora Efetiva do Departamento de Biologia \\ Grupo de Estudos da Complexidade e da Vida \\ Universidade Estadual da Paraíba - UEPB, Campina Grande/PB
}

Recebido em 4 de agosto de 2020

Aceito em 11 de agosto de 2020

\begin{abstract}
Resumo:
A Biofísica consiste em uma ciência transdisciplinar que integra temas e áreas diversas, constituindo um componente curricular essencial aos cursos das áreas das Ciências Biológicas e da Saúde. Entretanto, as pesquisas referentes ao ensino-aprendizagem desta área, apontam algumas questões desafiantes, tais como: abordagem estritamente física ou biológica dos conteúdos, escassez de propostas didáticas, bem como de pesquisadores e referenciais, em especial, no que concerne ao curso de Ciências Biológicas. Nesse contexto, a abordagem da Biofísica que apresentamos neste trabalho corresponde a uma incursão desta área na complexidade, tendo em vista um ensino de Biofísica mais integrativo. Assim, temos o objetivo de discutir as interconexões entre a termodinâmica do não-equilíbrio e as ciências da vida, suas influências no desenvolvimento de uma "nova Biofísica", bem como as suas implicações no ensino de Biofísica. Argumentamos que o ensino de Biofísica que emerge com os estudos da termodinâmica dos sistemas vivos, aproxima-se da construção de um conhecimento transdisciplinar ou complexo, evidenciando as articulações e/ou interconexões entre as proposições das ciências, entre os componentes curriculares e os diversos tipos de conhecimentos e contextos, de modo a contribuir para compreensões e explicações mais profundas e amplas sobre determinada temática ou problemática a que se propõe.
\end{abstract}

Palavras-chave: Complexidade, Biologia, Termodinâmica, Educação Biológica.

\section{Biophysics teaching: between equilibrium, non-equilibrium and self- organization in biological systems}

\begin{abstract}
:
Biophysics consists of a transdisciplinary science that integrates diverse themes and areas, constituting an essential curricular component to courses in the areas of Biological Sciences and Health. However, research related to teaching-learning in this area, points out some challenging issues, such as a strictly
\end{abstract}


physical or biological approach to content, shortage of didactic proposals, as well as researchers and references, especially concerning the Biological Sciences course. In this context, the Biophysics' approach that we present in this work corresponds to an incursion of this area in complexity, given more integrative teaching of Biophysics. Thus, we aim to discuss the interconnections between the non-equilibrium thermodynamics and the life sciences, their influences on the development of a"new Biophysics", as well as their implications for the teaching of Biophysics. We argue that the teaching of Biophysics that emerges with the studies of the thermodynamics of living systems, approaches the construction of a transdisciplinary or complex knowledge, evidencing the articulations and/or interconnections between the propositions of the sciences, between the curricular components and the various types of knowledge and contexts, in order to contribute to deeper and broader understanding and explanations of a given subject or problem.

Keywords: Complexity, Biology, Thermodynamics, Biological Education.

\section{Enseñanza de Biofísica: entre el equilibrio, el desequilibrio y la auto-organización en sistemas biológicos}

\section{Resumen:}

La Biofísica consiste en una ciencia transdisciplinaria que integra temas y áreas diversas, constituyendo un componente curricular esencial a los cursos de las áreas de las Ciencias Biológicasy de la Salud. Sin embargo, las investigaciones referentes a la enseñanza-aprendizaje de esta área, señalan algunas cuestiones desafiantes, tales como: abordaje estrictamente físico o biológico de los contenidos, escasez de propuestas didácticas, así como de investigadores y referenciales, enparticular en lo que se refiere al curso de Ciencias Biológicas. En ese contexto, el enfoque de la Biofísica que presentamos en este trabajo corresponde a una incursión de esta área en la complejidad, con vistas a una enseñanza de Biofísica más integradora. Así, tenemos el objetivo de discutir las interconexiones entre la termodinámica del no-equilibrio y las ciencias de la vida, sus influencias en el desarrollo de una "nueva Biofísica", así como sus implicaciones en la enseñanza de Biofísica. Argumentamos que la enseñanza de Biofísica que emerge con los estudios de la termodinámica de los sistemas vivos, se aproxima a la construcción de un conocimiento transdisciplinar o complejo, evidenciando las articulaciones y/o interconexiones entre las proposiciones de las ciencias, entre los componentes curriculares y los diversos tipos de conocimientos y contextos, a fin de contribuir a comprensi ones y explicaciones más profundas y amplias sobre determinada temática o problemática a la que se propone.

Palabras clave: Complejidad, Biología, Termodinámica, Educación Biológica.

\section{INTRODUÇÃO}

A origem da vida Terra é um assunto que há muito tempo desperta a nossa curiosidade, sendo alvo de inúmeras pesquisas e controvérsias. Existem várias versões a respeito desse tema, uma delas é o mito de Prometeu. Na narrativa apresentada por Bullfinch (2006), antes da criação da Terra e dos seus componentes, existia o Caos, uma massa confusa e sem forma que continha as sementes latentes das coisas. Através dos fenômenos naturais e da intervenção dos deuses, o mundo tal como conhecemos foi criado, assim como os animais e as plantas, porém faltava um animal mais nobre, no qual a essência divina pudesse habitar. 
Assim, Prometeu tomou uma porção de argila, misturou com água, e esculpiu o ser humano à semelhança dos deuses.

Prometeu, junto com seu irmão Epimeteu, foram os encarregados para garantir que os seres humanos e os outros animais, desenvolvessem as faculdades necessárias à sua sobrevivência, de modo que, a cada animal foram atribuídos dons variados, tais como, agilidade, coragem, força, dentre outros. No entanto, quando chegou a vez do ser humano, todos os recursos haviam sido gastos. Com o auxílio de Atena, Prometeu subiu ao Olimpo e acendeu uma tocha, trazendo o fogo para os seres humanos, dando-lhes, assim, a possibilidade de dominação de toda a natureza (BULLFINCH, 2006).

Ainda consoante ao referido autor, com o dom de manusear o fogo, os seres humanos construíram armas para caçar, equipamentos para o cultivo da terra, aquecimento de suas moradias, e, finalmente, criaram as moedas, viabilizando a expansão do comércio. Ao descobrir que o fogo havia sido roubado, Zeus ficou extremamente irritado, dirigindo a sua fúria e punição a Prometeu, ordenando que o acorrentassem no monte Cáucaso, onde um abutre devorava diariamente seu fígado, o qual para o seu sofrimento eterno, regenerava-se todos os dias.

Numa outra versão deste mito, conta-se que Prometeu roubou o fogo do Olimpo para soprar na sua escultura humana inanimada e dar-lhe vida (MEIS; RANGEL, 1998). De todo modo, o mito de Prometeu parece ser um dos registros mais antigos que faz menção à capacidade de manusear o fogo como um dom diferencial da espécie humana em relação às demais espécies, bem como correlaciona o calor do fogo (combustão) e a origem da própria vida humana (BULFINCH, 2006; MEIS; RANGEL, 1998).

Os estudos da neurocientista Herculano-Houzel (2017) sobre o desenvolvimento do cérebro humano, têm evidenciado que, o que nos tornou humanos e nos diferenciou das outras espécies, foi a nossa habilidade de utilizar o fogo para cozinhar. Cozinhar é uma habilidade que apenas a espécie humana é capaz de realizar, funcionando como uma prédigestão que dobra o rendimento energético dos alimentos de modo a ser possível obter mais energia em menos tempo, e relaciona-se com a alta concentração de neurônios no nosso córtex cerebral, aproximadamente 16 bilhões. Essa cortesia de 16 bilhões de neurônios do 
córtex cerebral, foi fundamental para desenvolvermos ciências, tecnologias, sociedades e culturas diversas.

É nesse contexto que os estudos da interação entre o calor e a matéria ao longo do tempo, isto é, da termodinâmica, em especial da termodinâmica do não-equilíbrio, também nos fornecem um paradigma sobre a origem da vida, o desenvolvimento dos ecossistemas, os seus padrões evolutivos ao longo do tempo (SCHNEIDER; KAY, 1994), bem como provoca reflexões sobre o papel da espécie humana nos ecossistemas e os seus modos de interação com a Natureza.

Os conceitos de irreversibilidade temporal e auto-organização que emergem com a termodinâmica dos sistemas afastados do equilíbrio, nos conduzem aos estudos da termodinâmica da complexidade biológica, os quais enfatizam, de acordo com Minayo (2011), os seres vivos como sistemas abertos, autônomos, trocando continuamente matéria, energia e informação com o ambiente ao qual estão integrados. Em concordância com a autora, essa compreensão consiste em uma das contribuições contemporâneas do pensamento complexo, interligando conhecimentos oriundos de diversas áreas da ciência, com destaque a autores como: Ludwig von Bertalanffy - biólogo que elaborou a Teoria Geral dos Sistemas; Ilya Prigogine - físico-químico, Nobel em Química em 1977, por seus estudos em termodinâmica do não-equilíbrio e teoria das estruturas dissipativas; Henri Atlan - biofísico, biólogo molecular e filósofo, propôs a teoria da auto-organização a partir dos ruídos e das crises; e Edgar Morin - antropólogo, sociólogo, filósofo, e pesquisador emérito do Centro Nacional de Pesquisa Científica de Paris.

Nessa perspectiva, a formalização da termodinâmica do não-equilíbrio, por Ilya Prigogine, ao final da década de 1940, e suas relações com as ciências da vida, ocasionaram uma mudança conceitual fundamental na história da Biologia, e da Biofísica em particular (BISCHOF, 2003), suscitando o questionamento levantado por Keller (2009): a Biologia está sendo reduzida a Física, ou a Física está sendo revivida, ressignificada, com a infusão dos processos da vida?

É nesse sentido que a abordagem dos conteúdos da Biofísica discutida no decorrer deste texto, corresponde a uma incursão desta área na complexidade, tendo em vista um Ensino de Biofísica mais integrativo. No entanto, não temos a finalidade de propor uma receita didática a ser seguida, uma vez que, de acordo com a especificidade de cada curso e 
formação profissional, emergem múltiplas abordagens possíveis. Sendo assim, não há uma Biofísica e um modo correto de ensinar Biofísica, existem Biofísicas que se conectam às dinâmicas dos contextos e currículos diversos.

Cabe destacar, portanto, a Biofísica como um componente curricular transdisciplinar, pois os conteúdos nela abordados percorrem diversas áreas científicas. Isto é, trata-se de um componente híbrido, que resulta de um processo de articulação e/ou interconexão entre vários componentes curriculares, no intuito de elaborar uma compreensão e uma explicação mais profunda e ampla de determinado problema ou tema científico (MINAYO, 2011).

Neste texto, de caráter ensaístico, temos o objetivo de discutir as interconexões entre a termodinâmica do não-equilíbrio e as ciências da vida, suas influências no desenvolvimento de uma "nova Biofísica", bem como as suas implicações no ensino de Biofísica. Para tanto, iniciaremos discutindo como a problemática relativa às máquinas térmicas levou à elaboração da segunda lei da termodinâmica, evidenciando a interface entre as ciências físicas e as ciências da vida. Em seguida, discorreremos sobre a termodinâmica do nãoequilíbrio, os processos de auto-organização em sistemas biológicos e as suas articulações com o desenvolvimento do pensamento biofísico. E, finalmente, apresentamos a relevância do estudo da termodinâmica da complexidade biológica para o ensino de Biofísica.

\section{MÁQUINAS TÉRMICAS E A SEGUNDA LEI DA TERMODINÂMICA: INTERFACES COM AS CIÊNCIAS DA VIDA}

A "ciência do fogo", reconhecida como ciência experimental no século XVIII, introduziu nas ciências modernas o que estas negavam nos estudos relativos à dinâmica: a irreversibilidade dos processos e a sua complexidade. Através das reações químicas provocadas pelo fogo, diversas transformações foram possíveis, tais como, dissolução, dilatação, fundição, evaporação, o que abriu margem para a queima de combustíveis com grande liberação de chamas e calor (PRIGOGINE; STENGERS, 1997). Dessa maneira, observouse que o calor liberado por meio da combustão, acarretava uma variação de volume, produzindo um efeito mecânico, de modo que, ao fogo atribuiu-se a capacidade de girar as máquinas térmicas, as quais no século XIX, consistiram em uma novidade técnica essencial 
para o surgimento da sociedade industrial, uma vez que as fontes de energias concebíveis até então eram provenientes dos ventos, da água, dos animais e das máquinas simples (PRIGOGINE; STENGERS, 1997; SANTOS, 2009).

Segundo Prigogine e Stengers (1997), através da investigação empírica sobre as condições nas quais o calor produziria "energia mecânica" para fazer girar um motor, emerge a termodinâmica. Assim, embora o ano de 1824 seja considerado o marco inicial de uma teoria da termodinâmica, com os estudos sobre a força motriz do fogo desenvolvidos por Sadi Carnot, cerca de dez anos antes, em 1811, Jean Joseph Fourier, afirmou em seu estudo técnico sobre a propagação de calor nos sólidos, que, a transferência calor entre dois corpos de distintas temperaturas é um fenômeno "sui generis", que não se reduz às simples interações mecânicas de vizinhança, suscitando os incômodos iniciais a respeito das fragilidades do modelo clássico de ciência, e que posteriormente questionariam o "demônio de Laplace" (PRIGOGINE; STENGERS, 1997).

A termodinâmica vai, então, constituindo-se como uma área do conhecimento científico que estuda as interações entre a matéria e o calor ao longo do tempo, sendo o calor considerado uma "forma de energia", tal como a energia elétrica, magnética, mecânica, dentre outras (MOURÃO JÚNIOR; ABRAMOV, 2009).

A primeira lei da termodinâmica (ou a lei da conservação da energia) corresponde ao princípio da conservação da energia, cuja formulação considerada mais abrangente é a do fisiologista e físico-matemático Hermann von Helmholtz, o qual em 1847, postulou que o estoque total de energia na natureza não poderia ser aumentado ou diminuído, pois essa quantidade de energia, assim como a quantidade de matéria, era eterna e inalterável (Nussenzveig, 2002). Isto é, em um sistema isolado a energia não pode ser criada ou destruída, apenas transformada, sendo assim, a energia se mantém conservada ou constante. A conservação da energia através das transformações que os sistemas físicos, químicos e biológicos podem sofrer, constitui a base das ciências da complexidade e o fio que conduz ao estudo e compreensão de uma multiplicidade de fenômenos e processos naturais (PRIGOGINE; STENGERS, 1997).

Partindo da compreensão de que a energia se mantém conservada ou constante apesar das transformações ocorridas, se um determinado processo acontece em um dado sentido ou sequência temporal, nada impede a reversibilidade do processo, isto é, que ele também ocorra 
no sentido inverso ou na sequência temporal inversa. No entanto, considerando a escala macroscópica, Mourão Júnior e Abramov (2009), levantaram as seguintes indagações: Seria possível utilizar toda a energia de um motor para realizar um trabalho? Por exemplo, uma máquina movida a gasolina que tem a função de produzir gasolina, seria capaz de produzir a mesma quantidade de gasolina que ela usa para funcionar? No dia a dia, podemos observar que um cubo de gelo derrete com o aumento da temperatura. É possível que o processo se reverta, que o cubo de gelo volte a ser exatamente como era, mesmo com alteração no ambiente que circunda tal massa de água, ou colocando-o em um freezer, ou com um intenso inverno? Ao trincar um copo de cristal, há alguma maneira de reverter essa rachadura de modo que o copo volte ao seu estado anterior? Com o passar do tempo, uma pessoa envelhece. É possível reverter esse processo?

De acordo com a lei da conservação da energia, é impossível aproveitar toda a energia, uma vez que parte dela é dissipada em forma de calor. Ou seja, em qualquer transformação, a energia se conserva, embora parte dessa energia seja dissipada na forma de calor tornandose inaproveitável para o próprio sistema, a quantidade de energia geral permanece constante, isto é, a energia não se perde, não se cria, se transforma. Cabe salientar que, de acordo com Schneider e Kay (1994), apesar da energia total permanecer constante, a qualidade da energia no sistema - a energia livre ou o conteúdo de exergia - pode ser alterada.

Os experimentos de Carnot sobre como aumentar o rendimento e a eficiência das máquinas térmicas, com o intuito de gerar maior economia de combustível e maiores lucros na sociedade capitalista que estava surgindo com a Revolução Industrial no século XIX, proporcionaram o reconhecimento de que o trabalho pode ser dissipado em calor, no entanto, não é possível converter totalmente o calor em trabalho, evidenciando, assim, a existência da irreversibilidade na natureza e levando a elaboração da segunda lei da termodinâmica.

Nesse contexto, Sadi Carnot elaborou um modelo teórico de uma máquina térmica ideal, estabelecendo o seguinte teorema: a) "Nenhuma máquina térmica que opere entre uma dada fonte quente e uma dada fonte fria pode ter rendimento superior ao de uma máquina de Carnot; b) Todas as máquinas de Carnot que operem entre essas duas fontes terão o mesmo rendimento" (NUSSENZVEIG, 2002, p. 213). O ciclo proposto por Carnot constitui um valor referencial para a avaliação da eficiência de qualquer máquina térmica funcionando entre duas temperaturas específicas, fornecendo subsídios para a elaboração da segunda lei da 
termodinâmica, tendo em vista dois enunciados distintos e equivalentes, propostos por Kelvin em 1851, e Clausius em 1850, respectivamente: a) “É impossível realizar um processo cujo único efeito seja remover calor de um reservatório térmico e produzir uma quantidade equivalente de trabalho; b) É impossível realizar um processo cujo efeito seja transferir calor de um corpo mais frio para um corpo mais quente" (NUSSENZVEIG, 2002, p. 207).

De acordo com Schneider e Kay (1994), a contribuição dos estudos de Carnot para a segunda lei pode ser sintetizada através da seguinte declaração: “É impossível para qualquer sistema passar por um processo no qual absorva calor de um reservatório a uma única temperatura e o converta completamente em trabalho mecânico, terminando no mesmo estado em que começou". Esta afirmação evidenciou a existência de uma nova função de estado de equilíbrio termodinâmico: a entropia (SANTOS, 2009).

Em concordância com a segunda lei, qualquer processo real ocorre numa direção que resulta em um aumento de entropia, desenhando uma espécie de "flecha do tempo" na natureza. Por exemplo, na natureza existem ciclos, são os padrões funcionais dos sistemas naturais, como as estações do ano, os ciclos menstruais, os dias e as noites. No entanto, são assimétricos, desiguais, cujas transformações acontecem no sentido do passado para o presente e dirigindo-se ao futuro, como uma flecha que é lançada e não retorna, e cuja percepção é possível, pois ao comparar o momento atual com o anterior percebemos uma diferença/assimetria entre eles (MOURÃO JÚNIOR; ABRAMOV, 2009).

Dessa forma, todos os fenômenos espontâneos e naturais são irreversíveis. Ou seja, os processos irreversíveis são unidirecionais no tempo, e remetem à ideia de uma seta ou flecha do tempo termodinâmica, que flui no sentido "passado $\rightarrow$ futuro", podendo ser associada com a ocorrência de um processo “ $i \rightarrow f$ ” em que um sistema vai irreversivelmente do estado inicial para o estado final. Vale lembrar que o ciclo da vida é também um processo irreversível, e que a seta do tempo é uma problemática em aberto (FREIRE, 2019).

De acordo com Prigogine e Stengers (1997, p.96), "para todo sistema isolado, o futuro é a direção na qual a entropia aumenta", exemplificando da seguinte maneira: $d S=d_{e} S+d S$, sendo $\mathrm{S}=$ entropia; $\mathrm{d} S \mathrm{~S}$ = o fluxo de energia entre o sistema e o meio; $\mathrm{d}_{\mathrm{i}} \mathrm{S}=\mathrm{a}$ entropia produzida no interior do sistema, isto é, as transformações irreversíveis. Por definição, $\mathrm{d}_{\mathbf{S}} \mathrm{S}$, terá sempre valor positivo ou nulo; e $\mathrm{d} S$, poderá ter valor negativo, nulo ou positivo, a depender dos sistemas serem isolados, fechados ou abertos. Assim, em um sistema isolado, o fluxo de 
entropia exterior é nulo, subsistindo apenas o termo de produção de entropia interna, $\mathrm{d} S$, de modo que $\mathrm{dS}=\mathrm{d} S \geq 0$. Nesse sentido, a segunda lei pode ser enunciada como: "qualquer processo real somente pode prosseguir em uma direção que resulte em aumento de entropia”, sendo a entropia a medida quantitativa da irreversibilidade, isto é, o número de possibilidades ou estados que um sistema pode assumir (SCHNEIDER; KAY, 1997).

Cabe então destacar que, de acordo com Mourão Júnior e Abramov (2009), existem três tipos de sistemas termodinâmicos: a) abertos - trocam matéria, energia e informação com outros sistemas de modo a ocorrer influências transformadoras entre si, por exemplo, os seres vivos; b) fechados - são capazes de realizar trocas de energia e informação, mas não há transferência de matéria, por exemplo, os computadores; c) isolados - são sistemas que hipoteticamente não interagem com outros sistemas, no entanto, esta classificação consiste em um artifício para falarmos de sistemas pouco interativos ou mais ou menos abertos, por exemplo, nosso sistema orbital solar, que sofre poucas transformações em sua simbiose com o restante do universo.

Prigogine (1996, p.25), lançou, então, a seguinte indagação: “Qual sistema poderia ser mais bem isolado do que o universo inteiro?" Apresentando, em seguida, dois princípios fundamentais à Termodinâmica, propostos por Clausius: a) "A energia do universo é constante; b) A entropia do universo cresce na direção de um máximo". Uma entropia crescente indica a direção do futuro, tanto no nível de um sistema local, como no nível do universo como um todo, sendo a diferenciação entre passado e futuro, o sentido em que a entropia aumenta (GERMANO, 2011).

No entanto, "como os fenômenos irreversíveis observados nos estudos da termodinâmica poderiam resultar de movimentos atômicos reversíveis, conforme a mecânica newtoniana?” (GERMANO, 2011, p.133) Para essa questão, as contribuições de Ludwig Edvard Boltzmann foram essenciais. Físico, atomista vienense, Boltzmann propôs uma interpretação da entropia em termos de movimento atômico, remetendo essa questão ao campo da estatística e das probabilidades. Em suma, ele observou dois níveis possíveis de descrição de um mesmo estado físico: 1) Macroscópico e relativo a um estado em grande escala, correspondendo, no caso de um gás, às medidas macroscópicas de pressão, temperatura e volume; 2) Microscópico e relativo a um estado em pequena escala, referindo-se às 
propriedades detalhadas dos átomos que compunham o sistema; no caso de um gás, a especificação das posições e velocidades de suas moléculas (GERMANO, 2011; SANTOS, 2009).

A partir do estado microscópico do sistema (posições e velocidades médias das moléculas), Boltzmann, determinou as quantidades associadas ao estado macroscópico (pressão, temperatura, volume), elucidando que a entropia refletia o número das diferentes formas pelas quais os microestados poderiam ser combinados para resultar em um macroestado específico. Assim, quanto maior o número de microestados para caracterizar um macroestado em particular, maior seria a entropia (SCHNEIDER; KAY, 1994).

A termodinâmica aprimorada pelos estudos de Boltzmann, apresentava uma compreensão da natureza em vias degenerativas cuja morte era inevitável da desordem aleatória, consistindo em uma visão pessimista dos sistemas naturais, os quais, nesse sentido, estariam avidamente buscando por equilíbrio. Em contraste, Darwin afirmava a crescente complexidade, especialização e organização dos sistemas biológicos ao longo do tempo (SCHNEIDER; KAY, 1997). Assim, se a entropia do universo tende a aumentar com o tempo, como os seres vivos poderiam criar e manter sua estrutura extremamente organizada e complexa?

Uma obra marcante nessa discussão é “What's life?”, de Schrodinger (1997). Ao discorrer sobre "os aspectos físicos da célula viva", o físico austríaco elucida que os seres vivos são estruturas organizadas, que se formam e se mantêm a partir da incorporação de elementos distribuídos de maneira desorganizada no ambiente. Para Prigogine (1996), sem a existência dos processos irreversíveis do não-equilíbrio, a vida no nosso planeta não seria concebível. A termodinâmica do não-equilíbrio estuda os processos dissipativos, que se caracterizam por um tempo unidirecional, conferindo uma nova significação à irreversibilidade, e de onde emergiram novos conceitos, como a auto-organização e as estruturas dissipativas, amplamente utilizados em estudos de áreas como a cosmologia, ecologia, ciências sociais, química e biologia.

Os organismos vivos consistem, portanto, em sistemas abertos distantes do equilíbrio, ou sistemas dissipativos, devido ao gradiente térmico provocado por fluxo energético contínuo advindo do Sol, ou de outro modo, podemos dizer que os seres vivos encontram-se em equilíbrio estacionário, onde há trocas de matéria e energia com o meio, cujo equilíbrio com o meio tem como resultado a própria morte (FILHO; PENHA-SILVA, 2005). Conforme Leão 
(1970), a vida consiste em uma constante tendência de equilíbrio entre o meio externo e interno, cuja realização é a própria morte. Em outros termos,

(...) Os animais necessitam comer para se manter vivos. Sabemos que os seres vivos são sistemas estáveis, longe do equilibrio. A todo instante, dentro de nós, processos são revertidos, porém à custa da energia de outros sistemas. (...) O envelhecimento mostra que, mesmo em sistemas dissipativos como os seres vivos, que consomem muitos joules de energia diariamente para manter a estabilidade longe do equilíbrio, ao longo do tempo, certos processos irreversíveis vão se sobrepondo, se acumulando (...) A morte chega quando as células não conseguem mais manter suas condições de homeostase $^{1}$ e o equilíbrio vai se impondo (concentrações iônicas tendem a se igualar, as temperaturas a cair, etc.) (MOURÃO JÚNIOR e ABRAMOV, 2009, p. 33).

Prigogine (1980) destaca que a finalidade do estudo dos processos irreversíveis se torna ainda mais nítida quando passamos a fenômenos biológicos ou sociais. Na Biologia, por exemplo, mesmo nas células mais simples, as atividades metabólicas envolvem múltiplas reações químicas acopladas, sendo necessário uma organização funcional extremamente sofisticada para a sua coordenação e regulação. Além disso, conforme o autor, as reações metabólicas requerem catalisadores específicos, as enzimas. Cada enzima executa uma tarefa específica. Sendo assim, ao observarmos a sequência complexa de atividades de uma célula, percebemos que ela está organizada de maneira semelhante a uma linha de montagem moderna.

$\mathrm{Na}$ natureza, os processos irreversíveis são a regra, os reversíveis, por sua vez, correspondem a idealizações, aproximações, condições necessárias para uma abordagem exaustiva que se adeque à exigência de uma descrição matemática completa, em concordância com Prigogine (1996). Para o autor, o estudo da termodinâmica do nãoequilíbrio constitui uma indispensável interface entre a física e as ciências da vida, visto que as demais leis físicas, como classicamente formuladas, descrevem um mundo e uma natureza idealizada e estável, sem pressupostos formais à evolução e à vida, a qual só é possível de ser concebida distante do equilíbrio estático.

\footnotetext{
${ }^{1}$ Elaborado pelo fisiologista Claude Bernard, o termo Homeostase refere-se aos estados estáveis de um ser vivo, is to é, as condições essenciais para que a multiplicidade de fenômenos metabólicos e fisiológicos possam ocorrer (Mourão Júnir \& Abramov, 2009).
} 


\section{TERMODINÂMICA DO NÃO-EQUILÍBRIO: ESTRUTURAS DISSIPATIVAS E AUTO- ORGANIZAÇÃO EM SISTEMAS VIVOS}

A termodinâmica aborda sistemas em três situações diferentes: a) sistemas em equilíbrio; b) sistemas que se encontram a uma certa distância do equilíbrio e tendem a retornar ao equilíbrio; c) sistemas afastados do equilíbrio e vinculados através de gradientes que os mantém a uma certa distância do equilíbrio (SCHNEIDER; KAY, 1997). Neste tópico, enfatizaremos a terceira categoria desses sistemas, isto é, os sistemas abertos ao fluxo de energia e matéria que se encontram em uma certa estabilidade afastada do equilíbrio, o que diz respeito aos seres vivos, e como esses sistemas vivos dissipam energia para o ambiente mantendo a sua organização ou os seus padrões de auto-organização.

O recorte que apresentamos referente à auto-organização em sistemas biológicos, compreende ao ressurgimento deste termo com o estudo dos sistemas termodinâmicos afastados do equilíbrio, no final das décadas de 1970 e 1980, tendo como fio condutor as contribuições de Evelyn Fox Keller para a história da auto-organização; os estudos do físicoquímico Ilya Prigogine, que lhe conferiram o Prêmio Nobel de Química em 1977, sobre a termodinâmica do não-equilíbrio, auto-organização e estruturas dissipativas; bem como a discussão sobre a termodinâmica da complexidade biológica apresentada por Schneider e Kay (1994; 1997).

"O que é um organismo? Qual é a propriedade ou a característica especial que distingue um sistema vivo de uma coleção de matéria inanimada?" (KELLER, 2005, p. 1069) Para a autora, essas foram indagações que fundamentaram a Biologia como uma ciência distinta no início do século XIX, e evidenciaram a inseparabilidade entre a história do termo “auto-organização" e a história da Biologia. Na versão da história da auto-organização apresentada por Keller (2009), as fronteiras entre organismos, máquinas e sistemas físicos são redesenhadas, evidenciando a separação entre organismos e máquinas, uma vez que, apesar das controvérsias, compreender o universo como um sistema auto-organizável longe do equilíbrio, possibilita uma variedade de estruturas improváveis, incluindo a própria vida, sem a necessidade de um projetista, piloto ou outro agente externo, oferecendo a possibilidade da construção de uma cosmologia científica finalmente liberta da dualidade platônica.

Os sistemas abertos e afastados do equilíbrio, tais como os sistemas vivos, mantêm a sua estrutura ou forma através da contínua dissipação energética, induzindo, assim, a 
formação de estruturas dissipativas, as quais conduzem a uma auto-organização do sistema. Desse modo, conforme Prigogine (1969), a auto-organização refere-se ao surgimento de estruturas dissipativas em sistemas distantes do equilíbrio e com baixa entropia, cuja organização se mantém tendo por efeito um aumento da entropia do sistema "global" no qual a estrutura está inserida. As estruturas dissipativas são, portanto, fenômenos de criação de organização longe do equilíbrio termodinâmico, ou de "ordem" a partir da "desordem", isto é, na presença da aplicação externa de gradientes energéticos, os sistemas vivos tendem a se afastar ainda mais do equilíbrio, desenvolvendo meios que permitam a promoção de maior degradação de energia, para reduzir o conteúdo de exergia ${ }^{2}$, através da tentativa de dissipar o gradiente de temperatura induzido na Terra pela radiação.

Vale lembrar que, de acordo com Prigogine (1996), a produção interna de entropia no sistema é sempre maior ou igual a zero, e a troca de entropia com o ambiente pode ser positiva, negativa ou zero. Desse modo, para que determinado sistema possa manter o seu estado de não-equilíbrio constante, é preciso que a troca de entropia seja negativa e igual a entropia produzida internamente - metabolismo, por exemplo. Estruturas dissipativas distantes do equilíbrio (e.g. células de convecção, células de Bénard, furacões, reações autocatalíticas e sistemas vivos), exibem uma organização coerente em resposta a uma entrada de energia externa, cuja transição de estruturas não-coerentes para coerentes consiste numa tentativa de afastar o sistema do equilíbrio (SCHNEIDER; KAY, 1997).

\begin{abstract}
Nos experimentos das células de Bénard, a superfície inferior de um líquido é aquecida e a superfície superior é mantida a uma temperatura mais baixa. O fluxo de calor inicial pelo sistema se dá por interação molécula-molécula. Quando o fluxo de calor alcança um valor crítico, o sistema toma-se instável e a ação molecular do líquido passa a ser coerente; surge a rotação convectiva, resultando em padrões de superfície hexagonais a espiralados coerentes e altamente estruturados (células de Bénard). Tais estruturas aumentam a velocidade de transferência de calor e de destruição de gradiente no sistema. A transição de estruturas não-coerentes para coerentes é a resposta do sistema às tentativas de afastá-lo do equilíbrio (SCHNEIDER; KAY, 1997, p.191).
\end{abstract}

\footnotetext{
${ }^{2}$ Exergia é um conceito central na discussão da ordem a partir da desordem, correspondendo a capacidade máxima de um sistema energético de realizar trabalho útil enquanto prossegue em direção ao equilíbrio com o ambiente (SCHNEIDER; KAY, 1997).
} 
Com o aumento do gradiente aplicado a determinados sistemas, aumenta também a habilidade do sistema de contrariar tais gradientes, isto é, de se opor a outros distanciamentos do equilíbrio, esse princípio proposto por Le Chatelier é um exemplo da segunda lei da termodinâmica reformulada ${ }^{3}$. Dessa forma, de acordo com Schneider e Kay (1997), quanto mais um sistema é distanciado do equilíbrio, mais ele desenvolve meios sofisticados para resistir a tal distanciamento, de modo que se as condições dinâmicas e/ou cinéticas possibilitarem, emergem processos de auto-organização para promover a dissipação de gradientes. Ainda de acordo com os autores, o surgimento de estruturas auto-organizáveis coerentes, portanto, é uma resposta de um sistema, na medida em que tenta resistir e dissipar gradientes externos que o levam ao afastamento do equilíbrio, ocasionando "ordem" a partir da "desordem" na formação de estruturas dissipativas.

Através dos estudos da termodinâmica do não equilíbrio em sistemas abertos, é possível revisitar os cenários onde se desenvolveram as rotas bioquímicas para a duplicação e tradução de ácidos nucleicos e demais macromoléculas indispensáveis à vida. Para Schneider e Kay (1997), a vida tem as suas origens no desenvolvimento de vias para a dissipação de gradientes térmicos e, devido a sua capacidade de reprodução, estratégias para manter as estruturas dissipativas em um ambiente físico flutuante também foram elaboradas. Assim, os autores argumentam que os sistemas vivos podem ser compreendidos como minitornados sofisticados, ou sistemas dissipativos dinâmicos, com memórias codificadas (DNA), que permitem a continuidade dos processos dissipativos, evitando, por exemplo, a reinicialização de todo o processo dissipativo mediante a eventos estocásticos.

Nessa perspectiva, o crescimento, o desenvolvimento e a evolução biológica são respostas dissipativas aos gradientes de energia induzidos pelo Sol. Ainda de acordo com Schneider e Kay (1994), o crescimento biológico resulta do acréscimo de mais dos mesmos tipos de vias de degradação de gradientes no sistema, e o desenvolvimento biológico ocorre quando emergem novos tipos de vias de degradação de gradientes energéticos. De modo que, quanto maior o sistema, maior a sua atividade de fluxo energético, mais numerosas e diversificadas serão as reações e as rotas disponíveis para a degradação do gradiente.

\footnotetext{
3 A Segunda Lei Reformulada enfatiza que a lei do "aumento da entropia" não corresponde ao enunciado geral da Segunda Lei da Termodinâmica (SCHNEIDER; KAY, 1994).
} 
Considerando o ciclo de constante interação dos seres vivos com o ambiente, vale reiterar o papel essencial do gene na preservação de informações para estratégias de autoorganização que funcionam, tendo em vista a continuidade da vida. Isto implica que a vida envolve a dialética entre os processos: "ordem a partir da desordem para gerar vida, e ordem a partir da ordem para dar-lhe continuidade" (SCHNEIDER; KAY, 1997, p.198).

Em o "Método II - A vida da vida”, Morin (2005a), apresenta e discute os termos genos e fenon, que embora distintos, são inseparáveis nos processos de auto-organização. O termo Genos refere-se ao genético, ao gerador, ao regenerador, a memória informacional inscrita no DNA, o dispositivo que gera as decisões e instruções celulares, correspondendo a organização da organização. Já Fenon, engloba as atividades produtoras, as trocas, o metabolismo, a homeostasia, a reação, a sensibilidade, o comportamento, correspondendo, portanto, a relação e a organização auto-ecológica. Daí o termo auto - eco - genos - fenos - organização.

De lado de genos, a ordem quase cristalina do DNA, cujas estruturas são extraordinariamente estáveis. Do lado de fenon, a instabilidade e a aptidão para as ligações e transformações moleculares das proteínas. Do lado de genos, uma "estrutura" químico-informacional parecendo formar "programas". Do lado de fenon, uma "máquina" termodinâmica com dissipações, flutuações, turnover. Do lado de genos, o desdobramento, o redesdobramento, a repetição. Do lado de fenon, a unicidade individual, a irreversibilidade do nascimento até a morte, a metamorfose (MORIN, 2005a, p.135).

Segundo Odum e Barret (2007), toda a biosfera possui a propriedade termodinâmica essencial para a criação e a manutenção de estados internos altamente organizados, isto é, uma baixa entropia interna, a qual é adquirida por meio da contínua dissipação de energia de alta utilidade (e.g. luz ou alimentos), em energia de baixa utilidade (e.g. calor). Em um ecossistema, por exemplo, a organização se mantém por meio da respiração da biomassa altamente complexa e organizada, que "expulsa" continuamente a "desordem", consistindo, assim, numa "estrutura dissipativa ecossistêmica". Desse modo, de acordo com os referidos autores, organismos e ecossistemas são sistemas abertos longes do equilíbrio termodinâmico, numa troca contínua de energia e matéria com o ambiente para reduzir a entropia interna e elevar a entropia externa. 
Conforme o seu crescimento e desenvolvimento, os ecossistemas aumentam sua dissipação total e desenvolvem estruturas mais complexas com maior fluxo energético, aumentando a sua atividade de ciclagem e desenvolvendo maiores diversidades e mais níveis hierárquicos para viabilizar a degradação de energia. Nesse sentido, a sobrevivência das espécies nos ecossistemas está relacionada a sua capacidade de canalizar energia tanto para sua própria produção e reprodução como para contribuir com os processos de autocatalização de modo a aumentar a dissipação total do ecossistema. Isto é, de acordo com o paradigma termodinâmico, o aumento sistemático da capacidade de degradação da energia solar é a chave para o desenvolvimento dos ecossistemas - exceto os ecossistemas de ventilação do fundo do mar, os quais obtêm energia através da temperatura e dos gradientes químicos que emanam dos fundos marítimos (SCHNEIDER; KAY, 1994).

As mudanças energéticas estão diretamente interligadas com a biodiversidade. Se não ocorressem as transferências de energia, as sucessivas mudanças essenciais à vida, tais como, crescimento, autoduplicação e síntese de moléculas complexas, não seriam possíveis (ODUM; BARRET, 2007). Assim, a dissipação de gradientes energéticos impulsionou a evolução biológica, uma vez que favoreceu o surgimento de organismos cada vez mais complexos. É provável que as primeiras estruturas dissipativas tenham surgido a partir de eventos aleatórios, e que a seleção natural tenha se encarregado de manter as estruturas que dissipavam energia de modo cada vez mais eficiente, aumentando, assim, a complexidade, sendo estas estruturas transmitidas através da informação genética (FILHO; PENHA-SILVA, 2005).

Se olharmos para a escala evolutiva, os organismos que surgiram mais recentemente são os que mais dissipam energia, conforme relatam Filho e Penha-Silva (2005). Tal evidência, de acordo com os autores, pode ser constatada através da taxa metabólica de animais homeotérmicos (regulam a sua temperatura corporal, mantendo-a praticamente constante aves e mamíferos, por exemplo) e pecilotérmicos (temperatura corporal varia de acordo com as condições ambientais - invertebrados, peixes, anfíbios e répteis, por exemplo). Evolutivamente, os pecilotérmicos surgiram primeiro do que os homeotérmicos, e a dissipação de energia através da taxa metabólica entre esses dois grupos evidencia que os homeotérmicos demandam muito mais energia, uma vez que para a regulação da sua temperatura interna é necessária uma produção de energia térmica que exige um metabolismo mais intenso do que o observado nos pecilotérmicos (idem, 2005). 
Segundo Odum e Barret (2007), as inter-relações entre produtores e consumidores, predadores e presas, bem como os inúmeros tipos e formas de organismos em um ambiente, são limitadas e controladas pelo fluxo de energia de formas concentradas (complexificação) para dispersas (descomplexificação). Assim, para os autores, "a humanidade é apenas uma das notáveis proliferações naturais que dependem da entrada de um fluxo contínuo da energia concentrada". De acordo com a lei da entropia e em contraste com o comportamento cíclico da matéria, as transformações de energia são unidirecionais, por isso a transferência de energia ao longo da cadeia alimentar de um ecossistema é denominada de fluxo de energia, de modo que, a cada etapa da transferência da energia de um organismo para outro, uma grande parte da energia é dissipada na forma de calor, diminuindo a quantidade de energia disponível, assim, a qualidade da energia restante pode ser consideravelmente aumentada. Dessa maneira, a entropia não é de todo negativa (ODUM; BARRET, 2007).

A dissipação do gradiente térmico recebido pela Terra advindo da radiação solar, inicia-se com as plantas, as quais aproveitam fotossinteticamente uma parte muito pequena da energia que recebem do sol (menos de 1\%), a maior parte é transformada em calor, que então sai da planta, do ecossistema, e da ecosfera, através de processos de evapotranspiração, por exemplo (ODUM; BARRET, 2007). Assim, de acordo com os autores, através das substâncias orgânicas produzidas nos processos de fotossíntese das plantas ou da quimiossíntese dos microrganismos, o mundo biológico restante obtém energia química potencial.

De modo geral, gradativamente, essa energia que as plantas incorporam é degradada na cadeia alimentar, de modo que, quanto maior a quantidade de espécies, maior o número de caminhos pelos quais a energia pode ser dissipada. Isso explica, por exemplo, o porquê de a biodiversidade ser maior no Equador: "esta é a região da Terra que recebe maior influxo de energia, devido ao ângulo, praticamente perpendicular, de incidência da radiação vinda do sol" (FILHO; PENHA-SILVA, 2005, p.36).

Em suma, do ponto de vista termodinâmico, os ecossistemas se desenvolvem de modo a aumentar a quantidade de exergia capturada e utilizada. Conforme se desenvolvem, há uma diminuição da quantidade de exergia da energia que sai, e assim, os ecossistemas passam a utilizar de maneira mais eficaz a exergia da energia que entra e, de modo simultâneo, a quantidade de energia que é capturada também aumenta (SCHNEIDER; KAY, 1994). À medida 
que a energia é absorvida e concentrada, há um aumento na diferenciação e na complexidade, caracterizando, segundo Di Corpo e Vannini (2012), a Lei da Sintropia. Assim, entropia e sintropia são forças opostas, porém complementares, uma vez que, enquanto a primeira refere-se a medida quantitativa da irreversibilidade, a "desordem", aos possíveis estados que um sistema pode assumir, a segunda diz respeito ao acúmulo de energia, a organização, conduzindo a diversidade de nichos ecológicos, por exemplo.

Nesse sentido, podemos ainda dizer que os ecossistemas tendem naturalmente a uma interação sinérgica, ou seja, uma interação entre os diversos seres vivos e demais componentes físico-químicos para a manutenção do equilíbrio estacionário da Terra, considerada como um superorganismo de acordo com a Teoria de Gaia, proposta por Lovelock (2010). Por outro lado, ecossistemas estressados tendem a apresentar menor potencial de degradação de energia e se assemelham aos primeiros estágios de sucessão ecológica, os quais, por sua vez, estão mais próximos do equilíbrio termodinâmico. Por exemplo, imaginemos uma pedreira, uma floresta recente e uma floresta antiga que recebem a mesma quantidade de energia solar por unidade de tempo. Considerando que quanto maior a complexidade de um ecossistema, mais eficiente ele se torna na degradação de energia solar, liberando menor radiação infravermelha, que resulta em uma temperatura de superfície menor, a pedreira irradiará mais radiação infravermelha do que a floresta recente, que, por sua vez irradiará mais que uma floresta antiga (FILHO; PENHA-SILVA, 2005).

Nesse contexto, cabe destacar, alguns desequilíbrios que vêm sendo provocados através das atividades da espécie humana nos ecossistemas, tais como: (a) o crescente desmatamento e queimadas de florestas - como a Amazônia para instituir sistemas de monoculturas com uso intensivo de agrotóxicos e tecnologias agressivas ao ambiente; (b) contaminação das nascentes hídricas; e, (c) o aumento da emissão de gases de efeito estufa. Esse tipo de interação interfere diretamente na ciclagem da matéria, levando a ruptura dos ciclos biogeoquímicos, tais como, o ciclo do carbono, da água, do nitrogênio. Provocando, de acordo com Leite e Silva (2020), rupturas ecossistêmicas que conduzem a um colapso ambiental.

O aquecimento global, por exemplo, é um fenômeno influenciado diretamente pelo ser humano, englobando os fatores acima mencionados e vários outros. Conforme exposto, a vegetação cria condições para manter o clima, o desmatamento intensivo da Amazônia pode 
levá-la a um ponto de não retorno às suas condições iniciais, pois a capacidade de autorregulação dos ecossistemas também é limitada. Isto implica que nesse ritmo de degradação o Bioma Amazônia está próximo de se tornar uma espécie de Savana. As ações da espécie humana, nesse sentido, estão provocando crescente estresse de animais e plantas, o que induz a liberação de inúmeros microrganismos patógenos, tais como os vírus.

É urgente que a espécie humana desenvolva outros modos de se relacionar com a natureza, em especial com a floresta tropical amazônica. A restauração de áreas degradadas através da agricultura regenerativa ou dos sistemas agroflorestais, praticada há muito tempo pelos povos originários, constitui uma alternativa para reestruturar a biodiversidade, mitigar as mudanças climáticas, promover autonomia e soberania alimentar, bem como gerar renda sustentável, proporcionando melhores condições de vida para a população, e, termodinamicamente, contribuindo para que os ecossistemas possam atuar de maneira sinérgica.

Para Kelson e Haken (1997), os conceitos físicos da formação auto-organizada de padrões, isto é, a sinergética, fornecem uma base para compreender os seres vivos e as suas inter-relações com o ambiente. No final do século XX, os autores salientaram que embora as leis fundamentais da física e da química sejam válidas para a Biologia, a sua estrutura conceitual ainda é muito restrita, sendo necessário elaborar novos conceitos que transcendam a mera descrição microscópica de sistemas.

Longe de esgotar as discussões sobre este assunto, que consideramos instigante e fundamental para o diálogo entre as ciências e a vida de maneira geral, e que além de requerer um tempo maior de aprofundamento, maturação e compreensão, está em constante metamorfose, destacamos que a ideia de auto-organização, de acordo com Morin (2005a), está dividida entre Termodinâmica e Biofísica, sem ainda ter realizado a sua efetiva incursão no pensamento biológico, permanecendo marginalizada com relação à teoria da vida. Mesmo que a história da auto-organização não seja assim tão recente, conforme descreve Keller (2009), continua sendo uma ideia nova, nascente, abstrata para a pesquisa empírica e prematura para uma aplicação prática, e, além disso, ainda não se auto-organizou conceitualmente. 


\section{BIOFÍSICA: UMA FÍSICA BIOLÓGICA OU UMA BIOLOGIA FÍSICA?}

O que é a Biofísica? Uma Física Biológica? Uma Biologia da Física? Segundo a Biophysical Society ${ }^{4}$, a Biofísica é o campo que aplica as teorias e métodos da física para entender como os sistemas biológicos funcionam. Mas, em que medida a metodologia e os conceitos físicos são modelos apropriados para as Ciências Biológicas? Os fenômenos e conceitos biológicos têm equivalentes nas Ciências Físicas? Segundo Mayr (1998), uma variedade de cientistas da área da Física, defendiam que todos os conhecimentos da Biologia poderiam ser explicados ou reduzidos às leis da Física. Em contrapartida, biologistas assumiram uma postura de autodefesa, reivindicando a autonomia da Biologia, o que gerou uma resistência considerável tanto de cientistas da física, como da filosofia essencialista. Embora esse movimento por uma Biologia como ciência autônoma, tenha ganhado força nas últimas décadas, Mayr (1998) afirma que o diálogo entre as ciências biológicas e físicas ainda é marcado por muitas controvérsias.

As investigações científicas no campo da Biofísica, por meio de instrumentos físicos, e a explicação de seus resultados utilizando conceitos físicos e matemáticos, têm sido realizadas desde 1840, e, como componente curricular, ela se estabeleceu apenas a partir da década de 1920, se não na década de 1940 (BISCHOF, 1996). No Brasil, temos como marco a fundação do Instituto de Biofísica, no Rio de Janeiro, em 1945 (ALMEIDA, 2012). A compreensão de que a Biofísica consiste no estudo dos fenômenos físicos aplicados à Biologia, ou na aplicação de leis físico-químicas da natureza não-viva, para o melhor entendimento dos sistemas biológicos, corresponde a uma abordagem reducionista que, para Bischof (1996), pode explicar o fracasso da Biofísica em desenvolver uma teoria da vida. $\mathrm{O}$ autor salienta que em 1940, J. R. Loofbowrow, escreveu que "não há um acordo explícito, nem mesmo entre biofísicos, sobre o que o termo biofísica representa".

Ainda nas primeiras décadas do século XX, segundo Capra (2009), houve um intenso debate entre os mecanicistas e vitalistas acerca dos fenômenos biológicos. Por um lado, os mecanicistas afirmavam que todos os fenômenos biológicos poderiam ser explicados pelas leis da física e da química. Por outro, os vitalistas defendiam a inserção de uma "força vital"

\footnotetext{
${ }^{4}$ A Sociedade Biofísica foi fundada na década de 1950 para liderar o desenvolvimento e a disseminação do conhecimento em Biofísica por meio de atividades, reuniões, publicações, divulgação, bem como sensibilização da comunidade científica e demais profis sionais (https://www.biophysics.org/about-bps/society-s-history).
} 
a essas leis, constituindo um elemento extrafísico dos fenômenos biológicos. Décadas depois, a ideia resultante desse debate, foi que, para uma compreensão plena dos fenômenos biológicos, era preciso abordá-los em três níveis descritivos: a biologia dos fenômenos observados, as leis da física e da bioquímica e a dinâmica não-linear dos sistemas complexos (CAPRA, 2009).

De acordo com Torres (2011), os sistemas biológicos não são estruturas reticulares estáticas. Os estudos relacionados à Termodinâmica do não-equilíbrio, formalizada por Prigogine, possibilitaram uma aproximação para discutir uma pergunta recorrente no campo das Ciências Biológicas: “O que é vida?”. Para o autor, qualquer que seja a química em que se baseia qualquer forma de vida, sistemas biológicos são sistemas dinâmicos, isto é, os seres vivos consistem em sistemas abertos em contínua troca de matéria, energia e informação com o ambiente, o que significa uma mudança contínua, uma vez que os sistemas biológicos têm a capacidade de emitir respostas a estímulos externos e internos, tendo, portanto, a capacidade de se adaptar e aprender.

Tendo em vista que a Biofísica tradicional tem sido, até agora, baseada na física clássica e na termodinâmica do equilíbrio, Bischof (2003) evidencia a necessidade de repensar essa área, em termos da revolução trazida pelos experimentos e interpretações da Física Quântica e da Termodinâmica do não-equilíbrio, por exemplo. Os conceitos de irreversibilidade temporal e auto-organização que emergem com a Termodinâmica dos sistemas afastados do equilíbrio, nos conduz aos estudos da Termodinâmica da Complexidade Biológica, e suscita o questionamento levantado por Keller (2009): a Biologia está sendo reduzida a Física, ou a Física está sendo revivida, ressignificada, com a infusão dos processos da vida?

$\mathrm{Na}$ ausência de uma uniformidade sobre o que constitui a Biofísica, Bischof (2003) afirma que é possível pensar em uma redefinição desse campo, considerando a diversidade de tendências recentes que convergem para esse conceito. A Biofísica que emerge com os estudos termodinâmicos dos sistemas vivos, evidencia a necessidade de se pensar uma "nova Biofísica ", ou uma Biofísica integral. Segundo o referido autor, uma Biofísica integral consiste

\footnotetext{
5 A abordagem da nova Biofísica proposta por Bischof (2003), é fundamentada na teoria quântica (sendo denominada também como "biologia quântica"), e na termodinâmica do não-equilíbrio, onde os organismos são compreendidos como sistemas abertos longe do equilíbrio. Assim, o autor destaca conceitos ou caracte rísticas centrais de uma Biofísica integral, a saber: a coerência, os estados quânticos macroscópicos, as interações de longo
} 
na percepção da interconexão fundamental dentro do organismo, bem como entre os organismos, e dos organismos com o ambiente, direcionando ao reconhecimento de que o estudo da vida pode fornecer "insights" sobre leis físicas básicas mais fundamentais do que as obtidas a partir de investigações da matéria não viva. Assim, uma compreensão da física dos seres vivos, não implica que a física deva substituir, mas sim apoiar uma compreensão biológica mais ampla e aprofundada, desenvolvendo uma teoria adequada da vida e equilibrando o domínio e a compreensão da vida (BISCHOF, 2003).

É importante salientar que não temos o propósito de apresentar alguma definição ou delimitação a respeito da Biofísica, uma vez que tentar polarizar a Biologia e a Física ou promover uma unificação, poderia nos levar a uma redução mutiladora, a um pensamento simplista ou reducionista, tal como discute Morin (2005b). É importante destacar que um ponto fundamental nas ciências da complexidade, de acordo com Capra (2012), é a compreensão das propriedades emergentes. De modo sucinto, a emergência corresponde às peculiaridades dos sistemas, que, por mais completos que pareçam ser, não podem ser deduzidos, ou reduzidos, aos conhecimentos das suas partes, em separado ou em combinações parciais, nem mesmo de modo teórico, ou seja, com a integração de várias partes em um sistema novas propriedades surgem.

Para elucidar essa discussão, Almeida (2017), apresentou a colocação de Hubert Reeves, que diz respeito às novas propriedades emergentes nas combinações, que não existiam em absoluto nos elementos isolados, por exemplo, "a molécula de água é um excelente solvente, que não é de forma alguma o hidrogênio e o oxigênio que a compõem", sendo um equívoco tentar explicar as propriedades da água a partir das propriedades do hidrogênio e oxigênio em separado, em suas particularidades. De modo semelhante, a Biologia e a Física possuem aspectos particulares intrínsecos que as constituem como áreas de construção do conhecimento científico, com os seus objetos de estudos e especificidades.

A Biofísica que emerge, portanto, não é de forma alguma estritamente física ou biológica e vice-versa, ou apenas, uma mera aplicação de conceitos e definições de uma área a outra, mas surge com novas propriedades e características, constituindo um campo do saber científico onde é necessário, tal como discute Minayo (2011), uma triangulação de

alcance, a não-linearidade, a auto-organização e a autorregulação, as redes de comunicação, os modelos de campo, a interconectividade e a inclusão da consciência. 
perspectivas, métodos, técnicas e análises que propiciem uma compreensão, interpretação e explicação da problemática ou temática a que se propõe.

\section{ABORDAGENS DE CONTEÚDOS DE BIOFÍSICA NO ENSINO SUPERIOR: REFLEXÕES A PARTIR DOS LIVROS-TEXTO}

Considerando que os livros-texto são amplamente utilizados como referenciais por estudantes e docentes, torna-se indispensável refletir sobre as abordagens dos assuntos relativos à Biofísica nestes materiais. De modo geral, as diferentes interpretações e tendências sobre o que exatamente é a Biofísica e a abrangência deste campo, está refletida em uma série de livros-texto contemporâneos e introduções de Biofísica, bem como na variedade nos títulos dos livros, que além da Biofísica, incluem, "Física Médica, "Física Médica e Biológica”, “Biologia Física", "Bases Físicas da Medicina e da Biologia”, por exemplo (BISCHOF, 2003).

A bibliografia recomendada para os cursos de Biofísica apresenta tópicos diversos e complexos, dentre os quais destacam-se a Biomecânica, Bioeletricidade, Radiação, Biotermodinâmica, dentre outros (MUÑOZ; FLORES; CASSIBA, 2011). Analisando esta bibliografia, os autores constataram que os guias de problemas e exercícios, que aparecem geralmente ao longo dos textos ou ao término de cada capítulo, referem-se principalmente, e quase que exclusivamente, a abordagens puramente físicas e essencialmente quantitativas, excluindo quase ou totalmente as questões referentes às ciências da vida. Além disso, evidenciaram que a Biofísica requer que tanto os aspectos físicos como biológicos sejam problematizados, sem que um campo se estabeleça sobre o outro, mas que sejam abordados através de uma perspectiva integral própria.

Ainda segundo os autores supracitados, a Biofísica não é um ramo da Física, nem da Biologia. Mas, independentemente dessas discussões epistemológicas, os problemas da Biofísica não são exclusivamente físicos, nem puramente biológicos, médicos ou fisiológicos. Os problemas da Biofísica, enquanto componente curricular, devem ser considerados de maneira integral, uma vez que levar em conta apenas aspectos físicos ou biológicos implicaria cair no reducionismo. Por exemplo, resolver problemas exclusivamente para cálculo conduz a um reducionismo quantitativo e, na melhor das hipóteses, a Biofísica poderia estar sendo 
reduzida à Física Aplicada. Por outro lado, considerar apenas aspectos do tipo biológicofisiológico-anatômico, de maneira geral resulta em uma redução descritiva e/ou qualitativa (MUÑOZ; FLORES; CASSIBA, 2011).

Refletindo sobre o que se ensina no componente de Biofísica, Corso (2009), destaca que os currículos dos cursos de graduação variam ao longo do país, sendo o componente curricular de Biofísica adaptado a realidade e/ou especificidades de cada curso. No que diz respeito a abordagem da Termodinâmica, o autor cita o livro-texto Biofísica escrito por Frumento (1974), no qual apenas um sétimo deste livro é dedicado para esse tema, sendo apenas uma pequena parte voltada a calorimetria animal que realmente interessa a área das Ciências Biológicas (Corso, 2009). Ainda de acordo com o autor, dentre os principais livrostexto utilizados na universidade em que atua, destacam-se: Garcia (2002), Leão (1982) e Okuno et al (1982).

No exemplar Biofísica Básica, elaborado por Heneine (2008), a Termodinâmica é abordada no capítulo 3, da parte I do livro, correspondente a Introdução à Biofísica. Ao longo do capítulo, aspectos conceituais da Termodinâmica são elencados, referentes à Primeira e a Segunda Lei, ao conceito de Entropia, Entalpia e Energia Livre, aos tipos de reações e efeitos observados, bem como a importância da catálise para a existência da vida. Um espaço ao final, correspondente a "leitura complementar", é destinado para abordar alguns aspectos da Termodinâmica aplicada aos Sistemas Biológicos, destacando tópicos como, energia e entropia em Biologia, bem como a relação entre entropia e a organização e informação em um sistema qualquer. Em seguida, em outra "leitura complementar", apresenta-se a diferenciação entre sistemas abertos e fechados, e entre processos reversíveis e irreversíveis na termodinâmica.

No livro Curso de Biofísica, dos autores Mourão Júnior e Abramov (2009), o primeiro capítulo "Organização da natureza" é dedicado à Termodinâmica e aos seus conceitos fundamentais. Na maior parte do capítulo, os autores contextualizam os padrões de organização e sistemas da natureza, discorrem sobre as características dos sistemas, tais como complexidade, estabilidade, equilíbrio, ordem, auto-organização e sistemas dissipativos, discutindo ainda sobre a irreversibilidade do tempo e a entropia. Nas páginas finais, descrevem e conceituam as leis da Termodinâmica, que, para os autores, consistem em enunciados da fundamentação das ideias discutidas ao longo do capítulo. 


\section{DIÁLOGOS ENTRE O ENSINO DE BIOFÍSICA E O PENSAMENTO COMPLEXO}

A Biofísica é um componente que integra o currículo de diversos cursos da área das Ciências Biológicas e da Saúde. É uma ciência interdisciplinar, complexa, uma vez que os temas estudados nessa área são frequentemente incluídos em outras, como a Fisiologia, a Bioquímica, além de ter desenvolvido áreas especificas de estudos, tais como, Biofísica Molecular; Biofísica celular; Bioeletricidade; Radiobiologia; Biofísica Ambiental, Biomecânica, dentre outras (FRUMENTO, 1972; GARCIA, 2002; HENEINE, 2008; MOURÃO; ABRAMOV, 2009). É um componente que contribui para que estudantes compreendam e posicionem-se criticamente frente a sociedade em que vivem e no mundo, sendo fundamental em temas que referem-se à qualidade de vida, contaminação ambiental, cuidado da saúde, benefícios e riscos do desenvolvimento científico e tecnológico, assim como sua relação com a política (MUÑOZ; VALES; CASSIBA, 2010).

As pesquisas acerca do ensino-aprendizagem dos temas relativos à Biofísica apresentam lacunas desafiantes para a compreensão dos conteúdos e/ou conceitos científicos que permeiam essa área. Cauduro e Ludke (2017) destacam: as abordagens restritas dos conceitos da Biologia ou da Física, sem a devida relação entre eles, a falta de docentes específicos da área, a carência ou ausência de propostas de alternativas didáticas nesse campo, e a escassez de pesquisadores e referenciais teóricos na área de Ensino de Biofísica.

Um dos maiores desafios da pesquisa em ensino de Biofísica está ligado a ausência de materiais bibliográficos e produções acadêmicas a respeito dessa temática (MOREIRA et al, 2018). Dentre as dificuldades de ensino deste componente observadas por docentes de Biofísica e apresentadas pelos autores supracitados, ressaltamos: a) Pouco conhecimento prévio do graduando, isto é, deficiências em Física e Matemática oriundas da educação básica, para lidar e identificar fenômenos biofísicos e os seus fundamentos físicos; b) Abordagem focalizada em memorização de fórmulas, conceitos, definições; c) Ausência de uma proposta pedagógica que seja significante e suficientemente justificável para a formação em Ciências Biológicas.

Tendo em vista a dimensão emergente e transdisciplinar deste componente, Muñoz, Flores e Cassiba (2011), sugerem uma "didática da Biofísica", para troca de ideias, discussões epistemológicas, construção de conteúdos específicos, desenvolvimento de materiais 
adequados, dentre outras atividades, com a finalidade de evidenciar a distinção entre a Biofísica e a Física para Ciências da Saúde, ou a Física de processos biológicos em geral. Assim, ainda de acordo com o referido autor, campos mais específicos também poderiam ser desenvolvidos, tais como ensino de Biomecânica, ensino de Bioeletricidade, ensino de Biotermodinâmica, entre outros.

Dentre as razões apresentadas pelos autores para a construção de uma didática da Biofísica, destacamos: a) A necessidade de reconhecer o lugar da Biofísica no design curricular, seus campos de aplicação, dentre outros; b) A importância de sondar os conhecimentos prévios dos estudantes, seus erros mais comuns, seus preconceitos, seus interesses e atitudes com relação a este componente, para melhorar a qualidade do ensinoaprendizagem de Biofísica; c) A compreensão de que a Biofísica não se reduz à memorização e aplicação de fórmulas e conceitos, sendo indispensável abrir espaço para as abordagens de situações reais, problematizando-as e contextualizando-as (MUÑOZ; FLORES; CASSIBA, 2011).

Além disso, uma didática da Biofísica pode colaborar no estabelecimento de relações com outros campos do conhecimento, como a História da Ciência, em particular da Biofísica, a didática geral, bem como da Física e da Biologia, a epistemologia da Biofísica, dentre outros. É importante destacar ainda que o incentivo a pesquisa sobre o ensino e a aprendizagem da Biofísica, sua divulgação científica, a adequada formação de professores, a produção de textos e softwares apropriados, a abordagem desse componente na educação escolar, e para a sociedade em geral, são aspectos relevantes de uma didática da Biofísica e pilares para o desenvolvimento tecnológico e científico de um país (MUÑOZ; VALES; CASSIBA 2010; MUÑOZ; FLORES; CASSIBA, 2011).

As discussões apresentadas por Muñoz, Flores e Cassiba (2011), a respeito de uma didática da Biofísica, são de suma importância para compreender e desenvolver um Ensino de Biofísica mais integrativo. Porém, neste trabalho, estamos distantes de propor uma didática que atenda a complexidade desta área. Quando levamos em consideração as múltiplas abordagens possíveis de acordo com a especificidade de cada curso e formação profissional, compreendemos que não existe uma Biofísica e uma receita de sucesso para ensinar Biofísica, existem Biofísicas dinâmicas que se conectam à dinamicidade curricular e aos contextos, tendo em vista que a Biofísica é um componente curricular necessário não 
apenas para o curso de Ciências Biológicas, mas também para outros cursos da área da Saúde, tais como Enfermagem, Fisioterapia, Medicina, dentre outros.

Segundo Morin (2005b), através da construção do conhecimento científico, elaboramos um universo de teorias, ideias, paradigmas, que remete tanto às esferas bioantropológicas do conhecimento, como ao seu enraizamento cultural, social e histórico. Sendo assim, a ciência não é o mero reflexo das leis da natureza, nós elaboramos. Assim, enquanto seres simultaneamente físicos, biológicos, sociais, culturais, psíquicos e espirituais, a complexidade reside na tentativa de conceber a articulação, a identidade e a diferença, entre estes aspectos. Por outro lado, um pensamento simplificador ou reducionista, tende a separar estes diferentes aspectos ou promover uma unificação por meio de uma redução mutiladora (MORIN, 2005b).

De acordo com Almeida (2017), a proposta central de uma educação para a complexidade está na religação e compartilhamento da diversidade dos saberes. Para nós, pensar um Ensino de Biofísica no âmbito da complexidade requer a compreensão de que a construção do conhecimento científico, assim como o processo de ensino-aprendizagem, é dinâmica, dialógica, com conexões múltiplas que metamorfoseiam em função das emergências. Esse processo proporciona o encontro de estranhezas e familiaridades, saberes desconhecidos e já conhecidos, tanto por estudantes, como docentes. Não se trata de improvisação, consiste em experiências de diálogos e intersubjetividades, reflexões de indivíduos abertos a aprender, reinventar, criar (FÁVERO; TAUCHEN, 2013; MORAES, 2008).

\section{CONSIDERAÇÕES FINAIS}

O ensino de Biofísica numa perspectiva transdisciplinar ou complexa, aproxima-se da construção de um conhecimento que evidencia as articulações e/ou interconexões entre as proposições das ciências, entre os componentes curriculares e os diversos tipos de saberes e contextos, de modo a contribuir para compreensões e explicações mais profundas e amplas sobre determinada temática ou problemática a que se propõe.

Nesse sentido, a termodinâmica do não-equilíbrio em uma abordagem Biofísica, evidencia que enquanto seres vivos, somos sistemas abertos, trocando constantemente 
matéria, energia e informação com outros seres vivos, com o ambiente que nos cerca e, consequentemente, com o universo, o qual só pode ser completamente isolado em termos hipotéticos. Enquanto seres vivos, também percebemos o ciclo básico da vida e que é impossível revertê-lo naturalmente, uma pessoa não nasce idosa, e uma pessoa idosa não se torna um bebê, de maneira espontânea, por exemplo. É possível notar, portanto, que todos os fenômenos que ocorrem na natureza são irreversíveis e que há uma assimetria nos eventos ou acontecimentos da nossa vida que nos permite perceber algo como passado, presente e futuro, semelhante a uma flecha do tempo que flui no sentido passado $\rightarrow$ futuro. Sendo o futuro alguma coisa perto de indeterminado ou imprevisível, ou ainda com numerosas possibilidades, mesmo com todas as "previsões científicas" e estatísticas apontando que...

Assim, vivendo em um ecossistema interconectado, interdependente, e em constante mudança, é fundamental pensar em nosso papel enquanto espécie humana. E isso implica que devemos compreender de maneira mais profunda as nossas conexões, tanto individuais enquanto espécimes, como coletivas - enquanto espécimes da espécie humana - e as relações que estabelecemos com os ecossistemas de maneira geral. Visto que a sobrevivência das espécies nos ecossistemas está diretamente ligada à sua capacidade de canalizar energia para sua própria produção e reprodução, bem como para contribuir com a dissipação energética total do ecossistema, a interação dos seres humanos com a Natureza, fundamentada em princípios antropocêntricos, mecanicistas e militaristas, violam sistematicamente a integridade dos ecossistemas e das demais espécies, diminuindo a capacidade de degradação energética dos ecossistemas. Ecossistemas estressados, por sua vez, se assemelham aos primeiros estágios sucessionais e estão mais próximos do equilíbrio termodinâmico.

À medida que, consoante a um modelo econômico antropocêntrico, mecanicista e globalizado, desmatamos, queimamos, contaminamos nascentes hídricas, invadimos o habitat de outras espécies e manipulamos animais e plantas, desrespeitamos a integridade dos ecossistemas e construímos um mundo interconectado através de doenças. Em concordância com Vandana Shiva, ecofeminista e física indiana, a emergência sanitária e social intensificada com a pandemia da Covid-19, está intimamente relacionada com a degradação ambiental, com a extinção e o desaparecimento de espécies, bem como com as mudanças climáticas. 
Nesse contexto, redesenhar uma compreensão do que é a Biofísica a partir dos estudos da termodinâmica da complexidade biológica e as suas implicações para o ensino deste componente nas universidades, especialmente para o curso das Ciências Biológicas, implica na discussão de temas que influenciaram mudanças paradigmáticas não apenas no campo da Física, da Biologia e da Biofísica, mas das ciências de maneira geral. Além disso, essa temática está intimamente relacionada ao surgimento da vida e às maneiras como os ecossistemas se desenvolveram permitindo a evolução de outras espécies - incluindo a humana, bem como à capacidade de autorregulação e os limites que o superorganismo Gaia apresenta ao modelo econômico vigente, o que evoca outros modos de pensar e interagir tanto com a natureza, como socialmente.

Esperamos que as discussões apresentadas neste texto, possam subsidiar outras pesquisas na área de Ensino de Biofísica, especialmente no que concerne a alternativas ou estratégias didáticas que levem em consideração a complexidade desta área. Além disso, esperamos que a termodinâmica da complexidade biológica em sua abordagem biofísica possa provocar reflexões sobre quais são os nossos próprios valores e princípios enquanto sistemas abertos afastados do equilíbrio, espécimes da espécie humana, uma dentre inúmeras outras espécies que habitam a Terra, ou, de que maneira estamos interagindo e contribuindo para que os ecossistemas possam atuar de maneira sinérgica. Enquanto docentes na área de educação em ciências, esperamos que essas discussões nos conduzam a um diálogo com mais empatia, à construção de relações equânimes fundamentadas no respeito e na ética do cuidado de modo a englobar os seres humanos e não-humanos. Desse modo, estaríamos construindo a base para uma consciência interconectada com a biodiversidade, um ponto de bifurcação para uma ética planetária.

\section{AGRADECIMENTOS}

À professora Ceiça Almeida do Grupo de Estudos da Complexidade da Universidade Federal do Rio Grande do Norte, pelo diálogo e obras que inspiraram as discussões apresentadas neste texto. À Maria Ruthe Gomes da Silva, doutoranda na área de Ensino de Física pelo Programa de Pós-Graduação em Ensino, Filosofia e História das Ciências da UFBA, 
pelas sugestões e dedicação ao revisar este trabalho. E à Coordenação de Aperfeiçoamento de Pessoal de Nível Superior (CAPES) por subsidiar parcialmente este estudo.

\section{REFERÊNCIAS}

Almeida, D. F. A contribuição de Carlos Chagas Filho para a institucionalização da pesquisa científica na universidade brasileira. História, Ciências, Saúde - Manguinhos. Rio de Janeiro; v. 19, n.2, p. 653 -668, 2012.

BIOPHYSICAL SOCIETY. What is Biophysics? Disponível em: https://www.biophysics.org/about-bps/society-s-history. Acesso em 14 de Fevereiro de 2019;

BISCHOF, M. Some remarks on the history of Biophysics (and its future). Current Development of Biophysics, v. 22, 1996.

Introduction to integrative biophysics. In: POPP, F. A.; BELOUSSOV, L. Integrative Biophysics - Biophotonics (pp. 1

- 115). New York: Springer Science \& Business Media Dordrecht, 2003.

BULLFINCH, T. O livro de ouro da mitologia: história de deuses e heróis. Tradução: David Jardim. Rio de Janeiro: Ediouro, 2006.

CAPRA, F. As conexões ocultas: ciência para uma vida sustentável. 11ª ed. São Paulo: Cultrix, 2009.

O ponto de mutação: a ciência, a sociedade e a cultura emerg ente. $30^{\mathrm{a}}$ ed. São Paulo: Cultrix, 2012 .

CAUDURO, P. J.; LUDKE, E. Revisão bibliográfica sobre o ensino de Biofísica: uma análise de artigos de 2004 a 2013. Vivências, v.13, n.24, p. $418-424,2017$.

CORSO, G. Os conteúdos das disciplinas de biofísica e a física. Revista Brasileira de Ensino de Física, São Paulo, v. 31, n. 2, p. $2703.1-2703.4,2009$.

DI CORPO, U.; VANNINI, A. The New Thermodynamics and Life Energy. Syntropy Journal, v. 2, p. 33 - 46, 2012.

FÁVERO, A. A.; TAUCHEN, G. Epistemologia da complexidade e didática complexa: princípios e desafios. Educação e Filosofia. Uberlândia, v. 27, n.53, p. 175 - 192, 2003.

FILHO, M. S. G.; PENHA-SILVA, N. Uma Abordagem Termodinâmica da Vida. Ciência Hoje, v.37, n.221, p. 34 -39, 2005.

FREIRE, W. H. C. Termodinâmica para licenciatura, um roteiro. 1ª ed. São Paulo: Editora Livraria da Física, 2019.

FRUMENTO, A. S. Biofísica. México: Editora Intermédica, 1972.

GARCIA, E. A. C. Biofísica. São Paulo: SARVIER, 2002.

GERMANO, M. G. Uma nova ciência para um novo senso comum. Campina Grande: EDUEPB, 2011.

HENEINE, I. F. Biofísica Básica. Rio de Janeiro: Atheneu, 2008.

HERCULANO-HOUZEL, S. A vantag em humana: Como nosso cérebro se tornou superpoderoso. São Paulo: Companhia das Letras, 2017.

KELLER, E. F. Ecosystems, organisms, and machines. BioScience, v. 55, n.12, p. 1069 - 1074, 2005.

Organisms, Machines, and Thunderstorms: A History of Self-Organization, Part Two. Complexity, Emergence, and Stable Attractors. Historical Studies in the Natural Sciences, v.39, n.1, p. $1-31,2009$.

KELSON, J. A. S.; HAKEN, H. Novas leis antecipáveis no organismo: a sinergética do cérebro e do comportamento. In: Murphy, M. P.; O'Neill, A. J. O que é vida? 50 anos depois. Especulações sobre o futuro da biologia (pp. 159 - 185). Tradução: Laura Cardellini Barbosa de Oliveira. São Paulo: UNESP, 1997.

LEÃO, M. A. C. Introdução à Biofísica. Recife, PE: Editora Universidade Federal de Pernambuco, 1970.

LEITE, D. A. R.; SILVA, L. F. A Temática Ambiental nos Cursos de Licenciatura em Física de Instituições de Ensino Superior Públicas Situadas no Estado de São Paulo. Revista Brasileira de Pesquisa em Educação em Ciências, v. 20, p. 41 - 69, 2020. Disponível em: https://doi.org/10.28976/1984-2686rbpec2020u4169. Acesso em 30 de Maio de 2020. 
LOVELOCK, J. The vanishing face of Gaia: A final warning. New York: Basic Books, 2010.

MAYR, E. O desenvolvimento do pensamento biológico: diversidade, evolução e herança. Brasília, DF: Editora Universidade de Brasília, 1998.

MEIS, L.; RANGEL, D. A respiração e a $1^{a}$ lei da termodinâmica, ou, A alma da matéria. Rio de Janeiro, RJ, 1998.

MINAYO, M. C. S. Da inteligência parcial ao pensamento completo: desafios da ciência e da sociedade contemporânea. Política \& Sociedade, v.10, n.19, p. $41-56,2011$.

MORAES, M. C. O paradigma educacional emergente: implicações na formação do professor e nas práticas pedagógicas. Em aberto, v.16, n.70, 2008.

MOREIRA, C. H.; ROCHA, G. B.; TENÓRIO, A. C.; SILVA, R. M.; ROCHA, I. C. P. A B iofísica na formação do biólogo e a opinião do s docentes formadores da área. In: Anais do 16 Congresso Internacional de Tecnologia na Educação, p. 1- 11. Recife, PE, 2018.

MORIN, E. O método II: a vida da vida. Porto Alegre: Sulinas, 2005a.

Ciência com consciência. Rio de Janeiro: Bertrand Brasil, 2005b.

MOURÃO JÚNIOR, C. A., \& ABRAMOV, D. M. Curso de Biofísica. Rio de Janeiro: Guanabara, 2009.

MUÑOZ, J. C.; VALES, M.; CASSIBA, R. Hacia una Didáctica de la Biofísica distancia en el planteamiento de problemas de Física Aplicada y de Biofísica. Una propuesta em Biomecánica. En: Libro de resúmenes de la 95 Reunión Anual de la AFA, 2010.

MUÑOZ, J. C.; FLORES, M. V.; CASSIBBA, R. Por qué es necesaria una Didáctica de la Biofísica. Anales AFA, v. 23, n.1, 2011.

NUSSENZVEIG, H. M. Curso de Física Básica 2: Fluidos Oscilações Ondas e Calor. São Paulo: Editora Edgard Blucher, 2002.

ODUM, E. P.; BARRET, G. W. Fundamentos de Ecologia. Tradução da 5ª edição americana. São Paulo: Thompson, 2007.

PRIGOGINE, I. O fim das certezas: tempo, caos e as leis da natureza. Tradução: Roberto Leal Ferreira. São Paulo: Editora da Universidade Estadual Paulista, 1996.

Company, 1980

From being to becoming: time and complexity in the physical sciences. San Francisco: W.H. Freeman and Structure, Dissipation and Life. In: Marois, M. Theoretical Physics and Biology (pp. 23 - 52). Amsterdam: NorthHolland, 1969

PRIGOGINE, I.; STENGERS, I. A nova aliança: metamorfose da ciência. Tradução: Miguel Faria e Maria Joaquina Machado Trincheira. Brasília, DF: Universidade de Brasília, 1997.

SANTOS, Z. T. S. Ensino de entropia: um enfoque histórico e epistemológico. (Tese de Doutorado). Programa de Pós-Graduação em Educação, Universidade Federal do Rio Grande do Norte, Natal, 2009.

SCHNEIDER, E. D.; KAY, J. J. Life as a manifestation of the second law of thermodynamics. Mathematical and computer modelling, v.19, n. $6-8$, p. $25-48,1994$.

Ordem a partir da desordem: a termodinâmica da complexidade biológica. In: Murphy, M. P.; O’Neill, A. J. O que é vida? 50 anos depois. Especulações sobre o futuro da biologia (pp. 186-201). Tradução: Laura Cardellini Barbosa de Oliveira. São Paulo: UNESP, 1997.

SCHRODINGER, E. O que é vida? $\mathrm{O}$ aspecto físico da célula viva, seguido de mente e matéria e fragmentos autobiog ráficos. Tradução: Jesus de Paula Assis e Vera Yukie Kuwajima de Paula Assis. São Paulo: UNESP, 1997.

TORRES, M. A. M. Biología de Sistemas... ¿qué biología de sistemas? Encuentros en la Biología, v. 4, n.136, p. 68 - 70, 2011.

\section{$(\mathrm{cc}) \mathrm{EY}$}

Este trabalho está licenciado com uma Licença Creative Commons - Atribuição 4.0 Internacional. 